\title{
Tooth Supported Overdenture as an Amazing Solution for the Patient: A Case Report
}

\author{
Ayoob Mutleb Alnafisah ${ }^{1, *}$, Mohamed R Mahmoud ${ }^{2}$ \\ ${ }^{1}$ Dental Intern, College of Dentistry, Qassim University, KSA \\ ${ }^{2}$ College of Dentistry, Qassim University, KSA \\ *Corresponding author: ayoub.alnafeesa@qudent.org
}

Received March 04, 2019; Revised April 10, 2019; Accepted April 19, 2019

\begin{abstract}
Background; Edentulous state of a patient can lead directly to impairment, functional limitation, physical, psychological, and social disability. Edentulism was found to have a significant effect on residual ridge resorption, which leads to a reduction in the height of alveolar bone and the size of the denture bearing area. Tooth supported over denture is a concept which improve the retention and stability of the final prosthesis significantly, and also maintain the proprioception. Bone is a dynamic tissue. The extraction of teeth results in the initiation of the bone resorption pattern. Here we are reporting a case with advantages of exploiting few remaining teeth to minimize alveolar ridge resorption and improvement of retention and support through using complete over denture which overcomes many problems encountered by conventional complete denture and removable partial denture patients.
\end{abstract}

Keywords: complete tooth supported overdenture, bone resorption, edentulism, abudments, aesthetics

Cite This Article: Ayoob Mutleb Alnafisah, and Mohamed R Mahmoud, "Tooth Supported Overdenture as an Amazing Solution for the Patient: A Case Report." International Journal of Dental Sciences and Research, vol. 7, no. 1 (2019): 21-24. doi: 10.12691/ijdsr-7-1-5.

\section{Introduction}

Edentulism is a debilitating condition and can be described as the "final marker of disease burden for oral health" [1]. The current prevalence of complete tooth loss patients has declined over the last decade, still edentulism remains a major disease worldwide, especially among older adults [2]. Edentulism has a series of deleterious consequences for oral and general health. Oral consequences vary from the well-known residual ridge resorption to an impaired masticatory function, an unhealthy diet, social disability, and poor oral health quality of life. Edentulous individuals are also at greater risk for different systemic diseases and an increase in mortality rate [3]. Bone loss is an ongoing process following tooth loss [4], affecting the mandible four times more than the maxilla [5].

The use of natural teeth as abutments for overdenture has become a realistic alternative to the extraction of remaining teeth over the past decades [6,7]. Overdentures support and/or retention are obtained using one or more teeth or roots, which are located above the denture's basal surface [8]. When making an overdenture, mechanical retainers may be used on a substructure; another option is the coverage of remaining roots with metal, which are also known as telescopic crowns, short-coping, long-coping, or attachment depending on the type of root coverage. The remaining teeth height will be determined by the analysis of the vertical dimension and teeth's vertical bone height $[8,9]$.
Comparing various treatment methods within each other, implants supported over dentures may be described as the first choice in well selected patients [10,11], while it can be considered an option for aesthetic long-term treatment for elderly patients $[12,13]$ and is may not indicated for individuals with poor general health status. However, it is economically inaccessible to numerous patients. In addition, it is important to highlight that in some cases, implant therapy cannot be performed immediately, requiring a temporary measure to replace the tooth until the healing process occurs. Although the concept of making overdentures is not new, a conservative approach in management of remaining dentition is the rationale for its application and should be preferred over total extraction [14,15]. Regarding the treatment procedure, teeth that are to be used for the short-coping method to retain an overdenture should be reduced to a level of 1-2 mm above the gingival margin with copings with at least $4 \mathrm{~mm}$ in height, which will help to avoid overdenture's fracture.

Rissin et al. in 1978 compared masticatory performance in patients with natural dentition, complete denture and over denture. They reported that the over denture patients had a chewing efficiency one-third higher than the complete denture patients [16]. There are many removable and fixed treatment options available for completely edentulous patients. A timely planned roots supported overdenture has been a proven mainstay of preventive prosthodontics therapy as it attempts to conserve the few remaining natural teeth/roots and reducing alveolar bone resorption. In addition the root-supported overdenture 
offers a variety of advantages, including secured prosthesis support, proprioceptive feedback, and economic and psychological benefits $[17,18]$. It has been observed that alveolar bone resorbs at a faster rate without the support of natural dentition. Retained roots maintain alveolar bone, which will support an overdenture and prevent rapid bone loss [19]. An overdenture preparation must involve assessment of the inter-occlusal distance, there must be sufficient space for roots, metal copings and possible attachments, together with an adequate thickness of the denture base material and artificial teeth, all without jeopardizing the strength of the denture [20].

\section{Case Report}

A 62 years old male patient reported to the Dental Clinic Center, College of dentistry, Qassim University, KSA. The patient was asked to replace his missing teeth due to difficulty in chewing and unpleasant appearance. The patient was systemically disease free.

Intraoral examination revealed a maxillary Kennedy's Class I modification two partially edentulous opposing mandibular Kennedy's Class I partially edentulous (Figure 1).

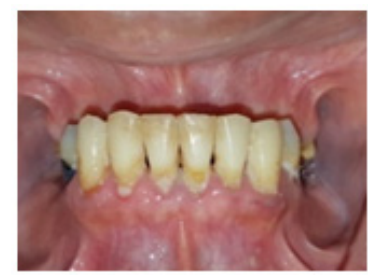

1.1

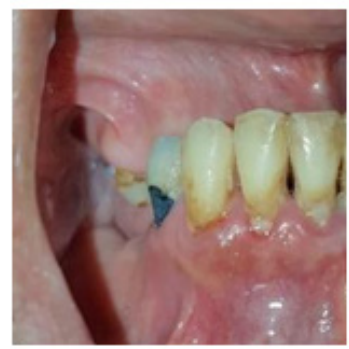

1.3

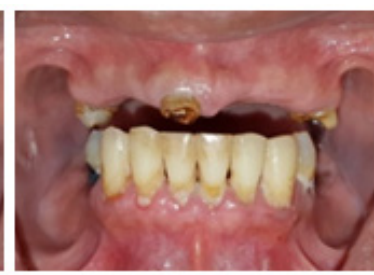

1.2

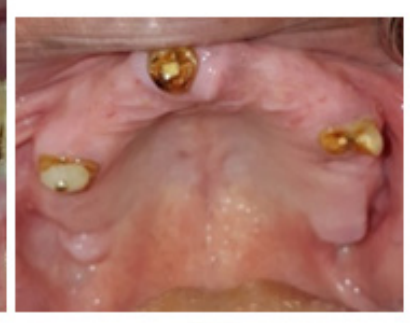

1.4
Figure 1.

Clinically, mobility was found in the remaining right and left lower first premolars. Periodontal findings were significant. There was calculus, gingival recession, pocket formation along with caries in the right and left lower premolars

The radiographs revealed a pathological lesion was detected in lower premolars and endodentically treated upper left premolar.

The classical treatment plan consists of Phase I: oral health education and scaling\& root planing, and Extraction of right and left lower premolars. Phase II: endodentic retreatment for upper left second premolar. Phase III: fabrication of teeth supported Complete over denture in the maxillary arch and acrylic partial denture Kennedy's class I in lower arch. Phase IV: Follow up, and post insertion care.
A preliminary maxillary and mandibular Alginate impression (Cavex CA37- BV 2003 RW Haarlem, the Netherlands) was made in stock tray and custom trays were constructed on the diagnostic cast.

A final maxillary impression was made using Zinc oxide impression material (Cavex Outline Eugenol impression paste- BV 2003 RW Haarlem, the Netherlands) and final mandibular impression was made using the regular body (Aquasil, Dentsply) . (Figure 2).

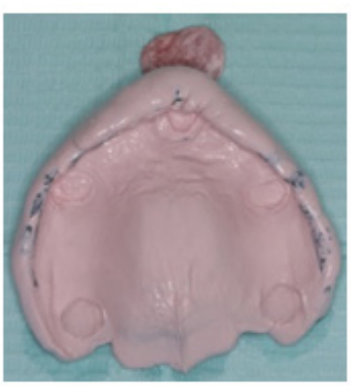

2.1

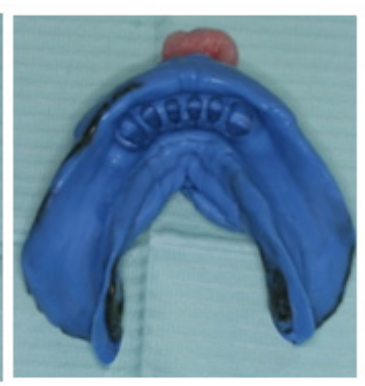

2.2
Figure 2 .

Cranio-maxilary relation recorded using Face bow transfer and the Maxillo-mandibular relations were recorded using centric and eccentric jaw relation record. (Dentatus Articulator- Dentatus AB /SE-16308 Spånga/ SWEDEN) which it is transferred to the semi adjustable articulator (Figure 3).

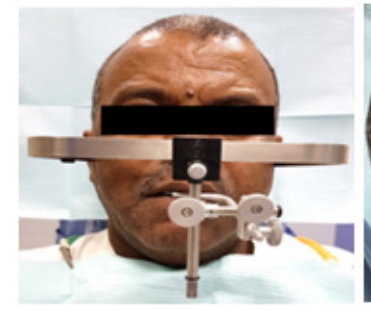

3.1

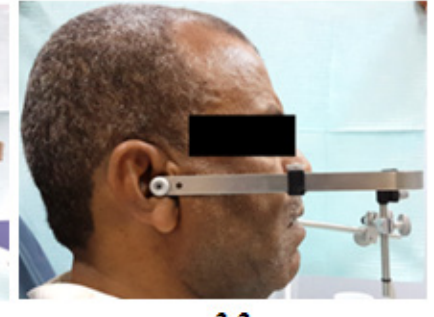

3.2

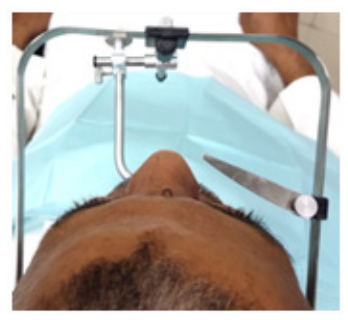

3.3

Figure 3 .

Teeth arrangement and trial placement of the upper and lower waxed up dentures were checked, with slight adjustment of the mandibular occlusal plane to can achieve the balanced occlusion. (Figure 4).

The dentures were acrylised in heat cure polymerizing resin (Lucitone 199Denture base resin Powder, Liquid, Dentsply). After finishing and polishing, the maxillary complete over denture and mandibular partial denture were checked for support, retention, stability, extension, fitting using pressure indicating past (Sultan Healthcare) and occlusion in the patient's mouth, and then the both dentures were delivered to the patient (Figure 5). 


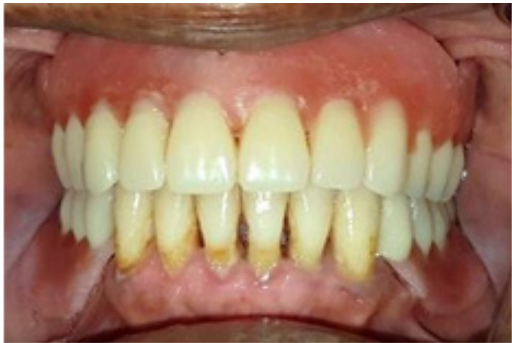

4.1

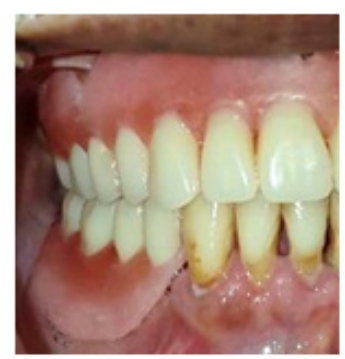

4.2

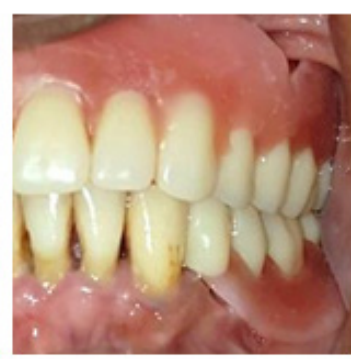

4.3
Figure 4.

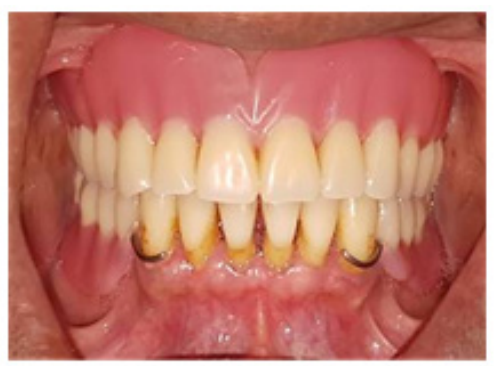

5.1

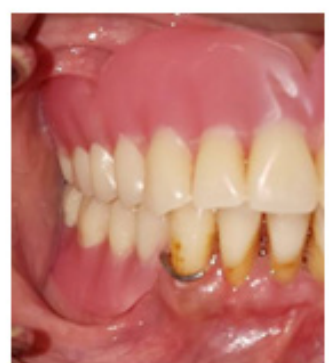

5.2

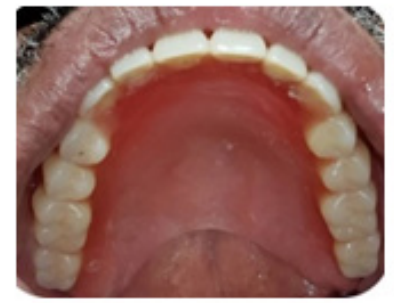

5.4

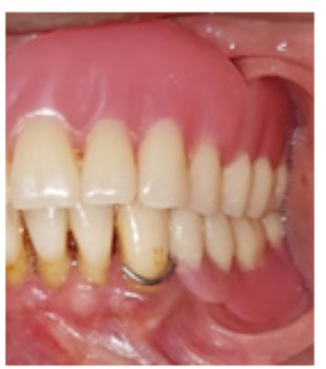

5.3

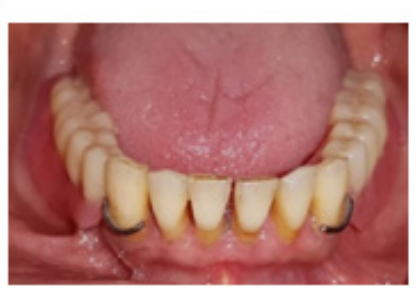

5.5
Figure 5.

The instructions were given. The post insertion followup period following denture delivery is critical for the success of denture. An appointment should be scheduled 24 hours after delivery, and then 3 days after delivery to eliminate any problem. Post insertion appointments should be periodically scheduled to eliminate further errors resulting from settling of dentures. During these appointments the dentures should be re-evaluated as regards, occlusion, retention, stability, and fitting.
At the end, we treated pseudo class III malocclusion by complete tooth supported overdenture.

\section{Discussion}

Edentulism is considered a major public health problem worldwide, despite the advancement in preventive dentistry [3]. Various studies have reported that there is a continuous resorption of the residual alveolar ridge in completely edentulous patient with complete denture and this continuous resorption may lead to serious Prosthodontic problem and difficulties both for the patient and the dentist [21]. It is also an agreement with Jain, et al who supported that preserving the remaining natural teeth have an excellent effect on retention and stability of dentures. It is also gives the patient a great psychological satisfaction [22].

In the first phase of treatment plan, we started with oral hygiene instructions, scaling and root planing to improve the periodontal condition of the remaining teeth, then we extracted the right and left lower premolars owing to have root caries and grade -2 mobility rendering them unpreservable. In the Second phase, retreatment for upper left second premolar was done to correct the inappropriate root canal obturation.. In the Third phase, Maxillary acrylic Tooth supported complete overdenture and Mandibular acrylic partial denture Kennedy's classI was done according to the conventional technique.

We used balanced occlusion scheme which required slight occlusal adjustment in the remaining mandibular anterior teeth. Mal-aligned, tilted or supra-erupted teeth in the opposing arch pose problems and should be corrected to achieve a balanced occlusion in patients who require tooth supported overdenture. Balanced occlusion is developed to improve the stability of the dentures during all functional and/or parafunctional movements of the mandible. Lack of occlusal balance may cause a variety of denture related problems including instability, mucosal inflammation, soreness, bone resorption and ultimate patient's dissatisfaction [23]. In fourth phase, frequent recall visits were conducted for occlusion refinement and correction of any border overextension. The patient was very satisfied with his new dentures from all the aspects including function and esthetics.

\section{Conclusion}

The over denture has proven innumerable advantages and applications compared with conventional complete denture. The success depends upon proper case selection with critical monitoring of various steps. Prosthodontic rehabilitation of cases like partial anodontia not only improves function and esthetics dramatically, but also psychologically boosts the morale of the patients more so when the individual is of younger age.

\section{Acknowledgments}

I would like to thank Dr. Shaul Hameed from department of Oral and Maxillofacial Radiology, College of dentistry, Qassim University for his consultation. 


\section{References}

[1] Cunha-Cruz J, Hujoel PP, Nadanovsky P. Secular trends in socioeconomic disparities in edentulism: USA, 1972-2001. Journal of Dental Research. 2007; 86(2): 131-6.

[2] Douglass CW, Shih A, Ostry L. Will there be a need for complete dentures in the United States in 2020? J Prosthet Dent. 2002; 87(1): 5-8.

[3] Emami E, de Souza RF, Kabawat M, Feine JS. The impact of edentulism on oral and general health. Int J Dent. 2013; 2013: 498305.

[4] Allen PF, McMillan AS. A review of the functional and psychosocial outcomes of edentulousness treated with complete replacement dentures. J Can Dent Assoc. 2003; 69(10): 662.

[5] Tallgren A. The continuing reduction of the residual alveolar ridges in complete denture wearers: a mixed-longitudinal study covering 25 years. J Prosthet Dent. 1972; 27(2): 120-32.

[6] Kalk W, van Rossum GM, Van Waas MA. Edentulism and preventive goals in the treatment of mutilated dentition. Int Dent J 1990; 40: 267-74.

[7] Van Waas MA, Jonkman RE, Kalk W, Van't Hof MA, Plooij J, Van Os JH. Differences two years after tooth extraction in mandibular bone reduction in patients treated with immediate overdentures or with immediate complete dentures. J Dent Res 1993; 72: 1001-4.

[8] Basker RM, Harrison A, Ralph JP. Overdentures in general dental practice. Part 5 - the use of copings and attachments. Br Dent J 1983; 155: 9-13.

[9] Zamikoff II. Overdentures - theory and technique. J Am Dent Assoc 1973; 86: 853-7.

[10] Leblebicioglu B, Rawal S, Mariotti A. A review of the functional and esthetic requirements for dental implants. J Am Dent Assoc 2007; 138: 321-29.

[11] De Rouck T, Collys K, Cosyn J. Immediate single-tooth implants in the anterior maxilla: a 1-year case cohort study on hard and soft tissue response. J Clin Periodontol 2008; 35: 649-57.
[12] Norton MR. Biologic and mechanical stability of single-tooth implants: 4- to 7-year follow-up. Clin Implant Dent Relat Res 2001; 3: 214-20.

[13] Tang CB, Ma JM, Tong X, Ding C, Li L. A clinical evaluation of implant dentures over 10 years. Shanghai Kou Qiang Yi Xue 2007; 16: $470-74$.

[14] Keltjens HM, Creugers TJ, van't Hof MA, Creugers NH. A 4-year clinical study on amalgam, resin composite and resin-modified glass ionomer cement restorations in overdenture abutments. J Dent 1999; 27: 551-55.

[15] Scotti R, Melilli D, Pizzo G. Overdenture supported by natural teeth: analysis of clinical advantages. Minerva Stomatol 2003; 52: 201-10.

[16] Prakash, Veenas, G. Shivaprakash, Nagarajappa, and Samrat Hegde. "Four and Two Tooth Supported - Conventional over Denture: Two Case Reports." International Journal of Oral Health Sciences 3, no. 1 (2013): 61.

[17] Morrow RM. Handbook of immediate overdentures. St. Louis: Mosby; 1978:48.

[18] Castleberry DJ. Philosophies and principles of removable partial overdentures. Dent Clin North Am 1990; 34: 589-92.

[19] Rissin L, House JE, Manly RS, Kapur KK. Clinical comparison of masticatory performance and electromyographic activity of patients with complete dentures, overdentures, and natural teeth. J Prosthet Dent 1978; 39: 508-11.

[20] Del Rio CE, Fielden JE, Grandich RA. Clinical appointment. III. Endodontics. In: Morrow RM, ed. Handbook of immediate overdentures. St. Louis: Mosby; 1978: 48.

[21] Burns DR. The mandibular complete overdenture. Dent Clin North Am. 2004; 48(3): 603-23.

[22] Jain JK, Prabhu CR, Zahrane MA, Esawy MS, Ajagannanavar SL, Pal KS. Cu-sil dentures - a novel approach to conserve few remaining teeth: Case reports. Journal of International Oral Health JIOH. 2015; 7(8): 138-40.

[23] Kam Wah Foong, Pravinkumar G. Patil. Fabrication of maxillary single complete denture in a patient with deranged mandibular occlusal plane: A case report, Saudi Dental Journal (2019) 31, $148-154$. 